\title{
Symbolic representation in animals: Emergent stimulus relations in conditional discrimination learning
}

\author{
THOMAS R. ZENTALL \\ University of Kentucky, Lexington, Kentucky
}

\begin{abstract}
When two initially unrelated stimuli are associated with the same event (e.g., many-to-one conditional discriminations), an emergent relation can develop between those stimuli, allowing them to be interchangeable in other contexts. The source of the emergent relation appears to be a common representation of the two stimuli, and the nature of the representation may be retrospective, involving one of the initial stimuli (probably the stimulus that first enters into association). These emergent relations have been implicated in the establishment of stimulus equivalent relations. However, the failure to find strong evidence for other emergent relations thought to be involved in stimulus equivalence (Sidman, 1990; e.g., bidirectional associations, transitive relations, and functional equivalence associated with one-to-many conditional discriminations) suggests that the mechanisms underlying the emergent relations found using transfer designs following many-to-one training are different from those presumed to underlie stimulus equivalence. On the other hand, evidence for the common representation of stimuli associated with the same arbitrary event extends the nature of those representations beyond those well-established effects found when the common events are biologically important (e.g., the differential outcomes effect).
\end{abstract}

One of the most important attributes of human communication is the ability to symbolically represent stimuli and responses. The most obvious example of this capacity is human language, in which arbitrary symbols (words) come to represent, or stand for, objects and actions. When words are assigned to objects, they can take on some of their characteristics. The words and the objects then come to have similar meaning, such that, for purposes of communication, the words can substitute for the objects that they represent. Symbols are not simply associated with the same response as the objects that they represent, but untrained emergent relations appear to develop between the symbol and the object itself.

Such emergent relations can also be demonstrated in learning tasks with simpler organisms (e.g., rats and pigeons). For example, when two unrelated stimuli are each associated with a common event, those stimuli may also

The research described in this article was supported by National Institute of Mental Health Grants MH 35376 and MH 45979 and by National Science Foundation Grants BNS 8418275, RII 8902792, BNS 9019080 , and IBN 9414589 . Important contributions to the research presented here were provided by David E. Hogan, Charles A. Edwards, Joyce A. Jagielo, Pamela Jackson-Smith, Janice N. Steirn, Lou M. Sherburne, Karen L. Roper, Daren H. Kaiser, Tom DeMarse, and especially Peter J. Urcuioli. Correspondence concerning this article should be addressed to T. R. Zentall, Department of Psychology, University of Kentucky, Lexington, KY 40506 (e-mail: zentall@pop.uky. edu).

Note: This article is one of those occasionally invited by the editor in which authors have the opportunity to provide a overview of their research programs.-Editor be treated similarly in other contexts (Honey \& Hall, 1989). An implication of this finding is that the similar treatment of the stimuli has caused them to become commonly represented (Grant, 1982; Urcuioli, 1996; Zentall, Sherburne, \& Urcuioli, 1995). But internal events, such as symbolic representations, are not directly observable. Evidence for symbolic representations can be inferred only after alternative accounts of the data, based on more direct or more observable mechanisms, have been ruled out. Furthermore, because it is not always possible to identify all of the alternative accounts, it is important to find convergent experimental evidence for the hypothesized relations. Such an approach may not only provide a strong case for the presence of the proposed emergent relations but, as we shall see, may also help to identify the nature of those representations.

\section{COMMON REPRESENTATIONS USING MANY-TO-ONE CONDITIONAL DISCRIMINATIONS}

\section{The Three-Phase Transfer Design: Evidence for Concept Learning}

Lea (1984) proposed that the formation of a nonsimilarity-based concept can be demonstrated by providing evidence of an emergent, untrained relation between unrelated stimuli. A procedure that can be used to provide such a demonstration can be described in three steps. First an organism is trained to sort stimuli according to a rule defined by the concept. That is, to all members of the concept, the organism is trained to make a 
particular response, $\mathrm{A}$, and to all nonmembers of the concept, to make a different response, B. If such training results in the formation of a concept, any new response learned to one or more members of the concept should also be acquired to the other members. Thus, to determine whether emergent relations have, in fact, developed among the members of the concept (rather than the acquisition of a series of independent stimulus-response associations), the organism can be trained to make a new response, $X$, to one or more members of the presumed concept and to make a new response, $Y$, to one or more nonmembers of the presumed concept. Finally, one can ask whether response $X$ also occurs to the remaining members and response $Y$ to the remaining nonmembers of the concept.

When this general design is applied to the simple case in which there are only two members and two nonmembers of the concept, we may have, for example, Stimuli $A$ and $B$ associated with Response 1 and Stimuli $C$ and $D$ associated with Response 2 . If we now associate Stimulus A with Response 3 and Stimulus $C$ with Response 4 , we can ask whether Stimulus B is also associated with Response 3 and Stimulus D with Response 4.

Such a design was used by Urcuioli, Zentall, JacksonSmith, and Steirn (1989; see also Urcuioli, Zentall, \& DeMarse, 1995). Pigeons were first trained on a many-toone conditional discrimination (matching-to-sample). Selection of one comparison stimulus was reinforced when the initial stimulus (or sample) was either a red hue or a vertical line, and selection of the alternative comparison stimulus was reinforced when the sample was a green hue or a horizontal line. During interim training, the red and green hues were associated with new comparisons. After interim training, the pigeons were tested with the remaining samples (the vertical and horizontal lines) and the new comparisons. The complete design of

Table 1 Common Coding: Many-To-One Transfer Design

\begin{tabular}{cccc}
\hline Group & Phase 1 & Phase 2 & Test \\
\hline Consistent & $\mathrm{R} \rightarrow \mathrm{V}$ & $\mathrm{R} \rightarrow \mathrm{C}$ & \\
& $\mathrm{G} \rightarrow \mathrm{H}$ & $\mathrm{G} \rightarrow \mathrm{D}$ & \\
& $\mathrm{V} \rightarrow \mathrm{V}$ & & $\mathrm{V} \rightarrow \mathrm{C}$ \\
& $\mathrm{H} \rightarrow \mathrm{H}$ & & $\mathrm{H} \rightarrow \mathrm{D}$ \\
Inconsistent & $\mathrm{R} \rightarrow \mathrm{V}$ & $\mathrm{R} \rightarrow \mathrm{C}$ & \\
& $\mathrm{G} \rightarrow \mathrm{H}$ & $\mathrm{G} \rightarrow \mathrm{D}$ & \\
& $\mathrm{V} \rightarrow \mathrm{V}$ & & $\mathrm{V} \rightarrow \mathrm{D}$ \\
& $\mathrm{H} \rightarrow \mathrm{H}$ & & $\mathrm{H} \rightarrow \mathrm{C}$ \\
\hline
\end{tabular}

Note- $R$, red; $G$, green; $V$, three vertical black lines; $H$, three horizontal black lines; $\mathrm{C}$, a white line-drawn circle; D, a white dot. All lines and shapes were projected on a black background. For each trial type, the first letter represents the sample and the second the correct comparison. In test, samples from Phase 1 that were not presented in Phase 2 were presented with the comparisons from Phase 2, and reinforced responding was either consistent with or inconsistent with the presumed common representations. From "Evidence for Common Coding in Many-to-One Matching: Retention, Intertrial Interference, and Transfer," P. J. Urcuioli, T. R. Zentall, P. Jackson-Smith, and J. N. Steirn, 1989, Journal of Experimental Psychology: Animal Behavior Processes, 15, pp. 264-273. Copyright 1989 by the American Psychological Association. Adapted with permission. this experiment (presented in Table 1) includes a control group for which the tested associations were inconsistent with the presumed common representations acquired during many-to-one training. Evidence for the development of an emergent relation between the red hue and the vertical line samples and between the green hue and the horizontal line samples came from choice of the new comparison associated with the red hue when the stimulus was a vertical line and of the new comparison associated with the green hue when the stimulus was a horizontal line. The transfer data from this experiment are presented in Figure 1.

Wasserman, DeVolder, and Coppage (1992) reported similar results when the four samples actually consisted of members of four classes of stimuli (photographs of flowers, chairs, people, and cars). In the original training, pigeons were trained to peck the top-right response key when the stimuli were exemplars of either flowers or chairs and to peck the bottom-left response key when the stimuli were exemplars of either people or cars. The training presumably established two higher order categories, flowers/chairs and people/cars. During interim training, the pigeons were trained to make a new response (e.g., peck the top-left response key) when, for example, an exemplar of a flower was presented and to make a different new response (e.g., peck the bottom-right response key) when, for example, an exemplar of a person was presented. On test trials, the pigeons showed evidence of the development of higher order categories by responding to the top-left response key when an exemplar of a chair was presented and by responding to the bottom-right response key when an exemplar of a car was presented.

The further generality of this phenomenon can be seen in the results of simple Pavlovian conditioning experiments involving only three stimuli (CSs) and two responses or outcomes (USs). Honey and Hall (1989) trained two groups of rats to associate Stimulus A with food and Stimulus B with no food. For rats in Group AC, Stimulus $C$ was associated with food (the same outcome as $\mathrm{A}$ but an outcome different from B), and, for rats in Group BC, Stimulus $C$ was associated with no food (the same outcome as B but an outcome different from A). All the rats were then trained to associate Stimulus C with shock, in a conditioned suppression design. Finally, Stimuli A and B were tested for conditioned suppression. Evidence for development of emergent relations was demonstrated by the greater suppression of responding to $A$ than to $B$ by Group $A C$ and the greater suppression of responding to B than to A by Group BC. Similar results have been reported by Spear and Molina (1987) and by Spear, Kraemer, Molina, and Smoller (1988) with infant rats.

Thus, the transfer design provides clear evidence for the development of emergent stimulus relations between stimuli associated with the same event. The remainder of this section will describe the results of experiments in which other designs have been used to demonstrate con- 


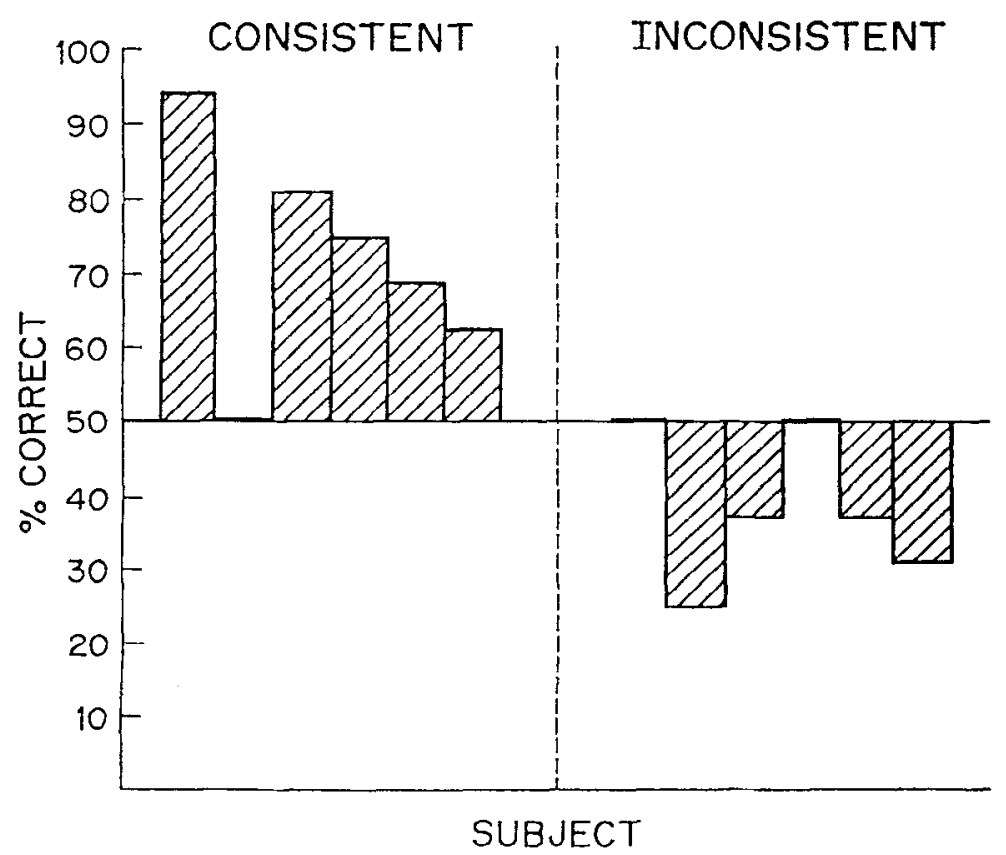

Figure 1. The first 16 trials of Phase 3 transfer following many-to-one conditionaldiscrimination training and interim training involving one pair of samples and a new pair of comparisons (see Table 1). From "Evidence for Common Coding in Many-toOne Matching: Retention, Intertrial Interference, and Transfer," by P. J. Urcuioli, T. R. Zentall, P. Jackson-Smith, and J. N. Steirn, 1989, Journal of Experimental Psychology: Animal Behavior Processes, 15, pp. 271 (Figure 5). Copyright 1989 by the American Psychological Association. Adapted with permission.

vergent evidence of emergent relations between stimuli associated with the same event.

\section{Interference/Facilitation Design}

A variation of the three-phase design is the interference/ facilitation design used by Zentall, Sherburne, and Urcuioli (1993). Following initial many-to-one conditional discrimination training, one of the pairs of samples from original training was associated with new comparison stimuli. Following acquisition of these new associations, retention intervals were inserted between the samples and comparisons on each trial, and training was continued until a high level of accuracy was achieved on the conditional discriminations. On test trials, one or the other of the remaining samples from original training was presented during the retention interval, and matching accuracy was compared with that on control trials with no stimulus presented during the retention interval. The design of this experiment is presented in Table 2 .

For pigeons that acquired the original many-to-one conditional discrimination quickly, facilitated accuracy was found when the interpolated stimulus was compatible with the initial sample on that trial (i.e., in training, the interpolated stimulus was associated with the same comparison as the sample). In addition, matching accuracy was disrupted when the interpolated stimulus was incompatible with the initial stimulus on that trial (i.e., in training, the interpolated stimulus was associated with a comparison that was different from the sample). These results are presented in Figure 2.

For pigeons that acquired the many-to-one conditional discrimination slowly, however, interpolation of either of the remaining samples from original training consistently interfered with matching accuracy. These pigeons treated the interpolated stimuli as if those stimuli were unrelated to the samples in the context of the new com-

Table 2

Common Coding: Many-To-One Interference/Facilitation Design

\begin{tabular}{lccl}
\hline Phase 1 & Phase 2A & Phase 2B & \multicolumn{1}{c}{ Test } \\
\hline $\mathrm{R} \rightarrow \mathrm{V}$ & $\mathrm{R} \rightarrow \mathrm{C}$ & $\mathrm{R} \rightarrow \mathrm{C}$ & $\mathrm{R} \rightarrow \mathrm{C}$ \\
$\mathrm{G} \rightarrow \mathrm{H}$ & $\mathrm{G} \rightarrow \mathrm{D}$ & $\mathrm{G} \rightarrow \mathrm{D}$ & $\mathrm{G} \rightarrow \mathrm{D}$ \\
$\mathrm{V} \rightarrow \mathrm{V}$ & & $\mathrm{R} \rightarrow \mathrm{V} \rightarrow \mathrm{C}$ \\
$\mathrm{H} \rightarrow \mathrm{H}$ & & $\mathrm{G} \rightarrow \mathrm{V} \rightarrow \mathrm{D}$ \\
& & & $\mathrm{R} \rightarrow \mathrm{H} \rightarrow \mathrm{C}$ \\
& & $\mathrm{G} \rightarrow \mathrm{H} \rightarrow \mathrm{D}$ \\
\hline
\end{tabular}

Note- $R$, red; G, green; V, three vertical white lines; H, three horizontal white lines; C, a white line-drawn circle; D, a white dot. All lines and shapes were projected on a black background. For each trial type, the first letter represents the sample and the second the correct comparison. In Phase 2B, a 2-sec delay was inserted between the sample and comparisons. In Phase 3, the delay was filled with either of the two remaining samples on some trials or remained empty on others. Other groups received line-sample training in Phase 2 and were tested with hues inserted during the delay. For half of the pigeons, the Phase 1 linesample/tine-comparison task was mismatching rather than matching. 


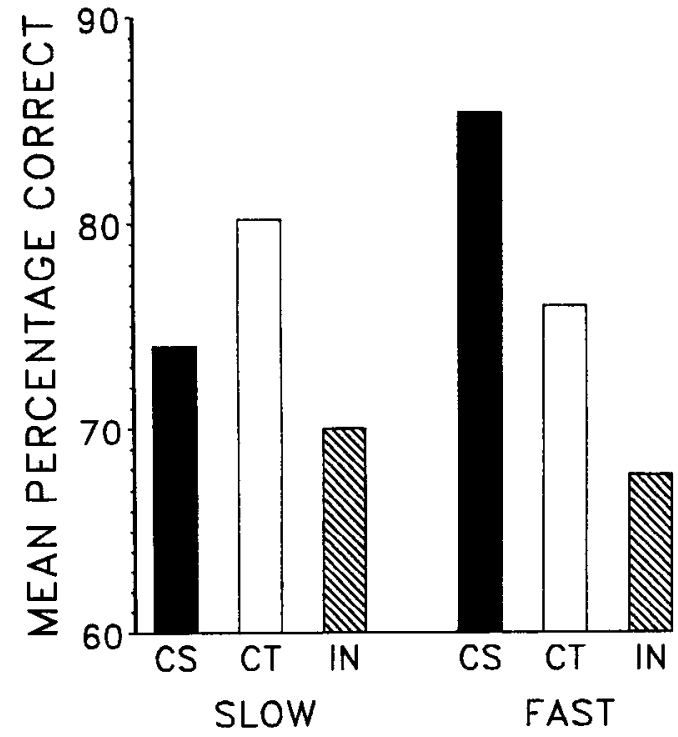

Figure 2. Test-trial accuracy on the 2-sec delayed condition discrimination for slow learners and fast learners following many-toone conditional discrimination training and interim training involving one pair of samples and a new pair of comparisons. Test trials included an interpolated stimulus presumed to have a representation consistent with the sample (CS), no interpolated stimulus (contmol, CT), or one inconsistent with the sample (IN, see Table 2). Copyright 1993 by Psychonomic Society Publications. Adapted from Zentall et al. (1993).

parisons. This finding is consistent with the hypothesis that these slow learners had not formed emergent relations between samples associated with the same event.

One source of differences in the rate of original learning between pigeons appeared to be the pair of samples that was initially more difficult to discriminate. Specifically, slow learners acquired the hue-sample/comparison associations at about the same rate as the fast learners. However, the slow learners acquired line-sample/comparison associations significantly slower than they acquired hue-sample/comparison associations, whereas the fast learners did not. This finding is consistent with the hypothesis that the fast learners were commonly coding samples associated with the same comparison, whereas slow learners were not. This finding may also help to shed some light on the nature of the emergent relation-an issue that will be addressed later.

\section{Partial Versus Total Reversal Design}

A somewhat different design that has been used to examine emergent stimulus relations following the acquisition of many-to-one conditional discriminations is the between-group partial versus total reversal design (Zentall, Steirn, Sherburne, \& Urcuioli, 1991). If emergent relations between stimuli make them more similar to each other, it should be relatively difficult to associate them with incompatible responses. Specifically, if, after training on a many-to-one conditional discrimination, one reverses the associations between one pair of samples (e.g., the lines) but not the other (i.e., the hues), learning should be relatively slow. In fact, reversal learning might be slower than it would be if all four of the sample comparison associations were reversed because, although a total reversal involves the reversal of twice as many associations, it also allows the emergent relations between samples to remain intact (e.g., red and vertical would still be associated with a common, albeit opposite, response, as would green and horizontal). The design of this experiment appears in Table 3.

Results reported by Zentall et al. (1991) were consistent with this hypothesis. More sessions were required for the pigeons to reverse the line-sample-comparison associations alone than to reverse the line-sample-comparison associations when the hue-sample-comparison associations were also reversed. Curiously, the same was not true for the partial hue-sample-comparison reversal group. For this group, there was no retardation of reversal learning produced by reversing only two of the four samplecomparison associations (see Figure 3 ). This asymmetry in results has theoretical implications (to be addressed later) for the nature of the emergent relations that form during many-to-one conditional discrimination training. It should be noted here, however, that this asymmetry in the partial versus total reversal effect rules out an alternative, and less interesting, account of the effect. Partial reversals might be learned slower than total reversals because the resulting schedule of reinforcement following a partial reversal is less discriminable from original training than is the change in schedule associated with the total reversal. When the pigeons are transferred to a partial reversal, the overall probability of reinforcement would be expected to drop to about $50 \%$, whereas, when they are transferred to a total reversal, the overall probability of reinforcement would be expected to drop to near $0 \%$. If detectability of the change in reinforcement schedule were responsible for the partial versus total reversal effect, however, one would expect comparable retardation for the hue-sample partial reversal group and for the line-sample partial reversal group.

The advantage of a total reversal over a partial reversal can also be shown when training involves simple successive discriminations in which two stimuli (e.g., a red hue and a vertical line) are trained as appetitive $S+s$

Table 3

Common Coding: Many-to-One Partial Versus Total Reversal

\begin{tabular}{cccc}
\hline \multirow{2}{*}{$\begin{array}{c}\text { Phase 1 } \\
\text { All Groups }\end{array}$} & Group Hue & Group Line & Group Hue-Line \\
\cline { 2 - 4 } $\mathrm{R} \rightarrow \mathrm{C}$ & $\mathrm{R} \rightarrow \mathrm{D}$ & $\mathrm{R} \rightarrow \mathrm{C}$ & $\mathrm{R} \rightarrow \mathrm{D}$ \\
$\mathrm{G} \rightarrow \mathrm{D}$ & $\mathrm{G} \rightarrow \mathrm{C}$ & $\mathrm{G} \rightarrow \mathrm{D}$ & $\mathrm{G} \rightarrow \mathrm{C}$ \\
$\mathrm{V} \rightarrow \mathrm{C}$ & $\mathrm{V} \rightarrow \mathrm{C}$ & $\mathrm{V} \rightarrow \mathrm{D}$ & $\mathrm{V} \rightarrow \mathrm{D}$ \\
$\mathrm{H} \rightarrow \mathrm{D}$ & $\mathrm{H} \rightarrow \mathrm{D}$ & $\mathrm{H} \rightarrow \mathrm{C}$ & $\mathrm{H} \rightarrow \mathrm{C}$ \\
\hline
\end{tabular}

Note-The first letter of each pair represents the sample $(R$, red; $G$, green; V, vertical; $H$, horizontal), and the second letter represents the correct comparison (C, circle; $\mathrm{D}$, dot) 


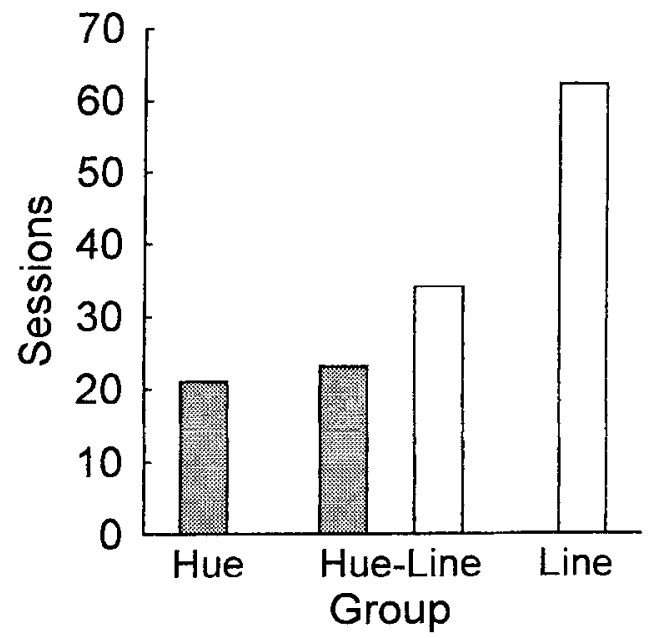

Figure 3. Acquisition (to a criterion of $90 \%$ correct) of partial reversal (Groups Hue and Line) and total reversal (Group Hue-Line) after many-to-one conditional-discrimination training. From " $\mathrm{Com}$ mon Coding in Pigeons Assessed Through Partial Versus Total Reversals of Many-to-One Conditional and Simple Discriminations," by T. R. Zentall, J. N. Steirn, L. M. Sherburne, and P. J. Urcuioli, 1991, Journal of Experimental Psychology: Animal Behavior Processes, 17, p. 196 (Figure 1). Copyright 1991 by the American Psychological Association. Adapted with permission.

and two other stimuli (e.g., a green hue and a horizontal line) are trained as $\mathbf{S}-\mathbf{s}$. When the outcomes associated with only the line samples are reversed, acquisition of the reversal is slower than when the outcomes associated with hue samples are also reversed (Zentall et al., 1991, Experiment 2; see also Nakagawa, 1986).

\section{Sample Discrimination Design}

A property of the emergent relation produced by the association of two stimuli with a common event is that an acquired equivalence of cues should result (i.e., there should be a high degree of generalization between the cues that is not based on physical similarity; Hall, 1991). A corollary of this proposition is that an acquired distinctiveness of cues should result when the two stimuli are associated with different events (i.e., there should be very little generalization between the stimuli). One means of assessing the acquired generalization between two stimuli is to train animals to discriminate between them. If emergent relations have developed between two samples associated with the same comparison stimulus, it should be more difficult to acquire a simple successive discrimination between them than between two samples associated with different comparisons.

Kaiser, Sherburne, Steirn, and Zentall (1997) tested this hypothesis by first training pigeons on a many-toone conditional discrimination in which red hue and vertical line samples were associated with a circle comparison and green hue and horizontal line samples were associated with a dot comparison. The pigeons were then trained on a simple successive discrimination involving the four samples from original training. Two of the stimuli were followed by food $(S+s)$, whereas the remaining stimuli were followed by the absence of food $(S-s)$. Those pigeons for which the two $S+s$ (and the two $S-s$ ) were associated with the same comparison during original training acquired the Phase 2 discrimination significantly faster than did pigeons for which the two $S+s$ (and the two $S-s$ ) had been associated with different comparisons. In other words, if the successive discrimination required disruption of the presumed emergent stimulus relation, acquisition was relatively retarded. Thus, training with many-to-one matching decreases the discriminability between samples associated with the same comparison.

\section{Slope of the Retention Functions}

When variable delays are inserted between the sample and comparison stimuli of a conditional discrimination, the slope of the resulting retention function provides a measure of sample memory. Using the slope of the retention function as a relative measure, sample memory appears to be affected by a number of variables, including the salience, or discriminability, of the samples. For example, there is evidence that hue samples are remembered better (or longer) than are line orientation samples (i.e., the slope of the retention function on hue sample trials is typically flatter than it is on line orientation sample trials; Farthing, Wagner, Gilmour, \& Waxman, 1977; Urcuioli et al., 1989; Zentall, Urcuioli, Jagielo, \& Jackson-Smith, 1989).

When training involves the many-to-one mapping of samples onto comparisons and one hue and one line orientation are mapped onto the same comparison, however, the slopes of the retention functions for hue and line orientation sample trials are almost identical (Urcuioli et al., 1989; Zentall et al., 1989). Similarity in the slopes of the retention functions for hue and line orientation samples following many-to-one conditional discrimination training (relative to other mapping conditions, e.g., one-to-many and one-to-one; see Figure 4) is consistent with the hypothesis that, under many-to-one mapping conditions, samples associated with the same comparison are commonly represented.

\section{THE NATURE OF THE EMERGENT RELATIONS}

Two alternative mechanisms have been proposed to account for the kind of emergent relations that appear to develop between samples associated with the same comparison following many-to-one conditional discrimination training.

\section{The Prospective Coding Hypothesis}

According to the prospective coding hypothesis (Grant, 1982), during conditional discrimination learning, sam- 

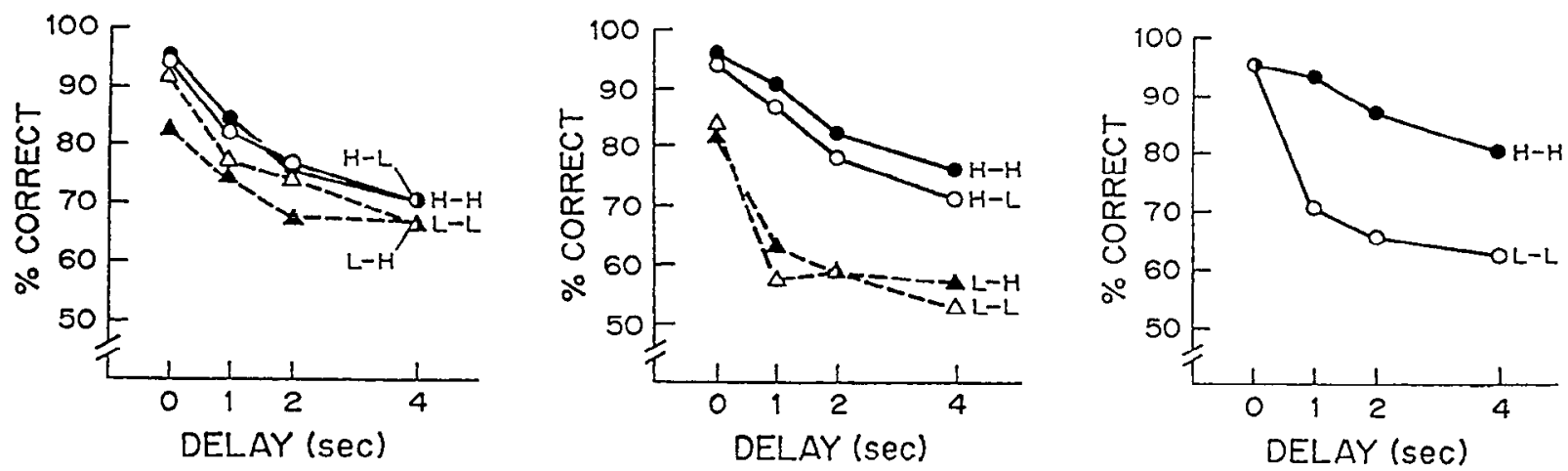

Figure 4. Retention test on trials with hue samples and hue comparisons $(\mathrm{H}-\mathrm{H})$, hue samples and line comparisons $(\mathrm{H}-\mathrm{L})$, line sample and hue comparisons $(\mathrm{L}-\mathrm{H})$, and line samples and line comparisons $(\mathrm{L}-\mathrm{L})$. In the left panel, pigeons were trained on many-to-one matching (the comparison dimension was varied between subjects). In the center panel, pigeons were trained on one-to-many matching (the sample dimension was varied between subjects). In the right panel, pigeons were trained on one-to-one matching (both the sample and the comparison dimension were varied between subjects). Adapted from Zentall et al. (1989). Copyright 1989 by Psychonomic Society Publications.

ples are coded in terms of a future event, the comparison to which a response will be reinforced. For example, if presentation of a red hue sample indicates that a response to the circle comparison will be reinforced, the red sample will be coded as circle, and, if a delay is inserted between the sample offset and comparison onset, the intention to respond to the circle comparison is what is maintained in memory during the retention interval. Furthermore, if presentation of a vertical line sample also indicates that a response to the circle comparison will be reinforced, it too will be coded as circle. Thus, because the samples are commonly coded in terms of the comparison stimulus to which a response is anticipated, the common representation is considered to be prospective in nature.

Support for this prospective coding account of transfer effects found following many-to-one matching-tosample training was reported by Grant (1982). In this study, pigeons were trained to respond to one comparison if the sample had been a red hue, food, or 20 pecks to a white stimulus and to respond to the other comparison if the sample had been the absence of food, a green hue, or 1 peck to a white stimulus. On test trials, Grant (1982) presented each pigeon with one, two, or three samples associated with the same comparison, and those samples were either the same (e.g., red-red-red) or different (e.g., red-food-20 pecks). In addition, delays of various duration were inserted between the samples and the comparisons.

Grant (1982) argued that, if the pigeons were coding the samples in terms of the correct comparison, the retention functions should not depend on which of the three samples was presented or on whether multiple samples were the same or different. According to Grant (1982), accuracy should depend only on the number of samples presented (i.e., the number of times that the prospective code was generated). If, however, the samples had different representations, the retention functions might depend on which samples were presented and whether the samples were the same or different (under the assumption that different representations would likely be forgotten at different rates). Consistent with the prospective coding account, Grant (1982) found that accuracy was affected by the number of samples presented but not by the sample type.

Stronger support for the prospective coding hypothesis comes from research involving many-to-one training, reported by Grant (1991), in which red hue and food samples were associated with one comparison and green hue and no-food samples were associated with the other comparison. Typically, when food and no-food samples are mapped onto comparisons, one to one, the retention functions obtained following training tend to diverge. That is, matching accuracy on food sample trials is high when the retention interval is short, but it decreases rapidly as the retention interval increases, whereas matching accuracy on no-food sample trials is also high when the retention interval is short, but it remains high and relatively flat with increasing retention interval. This finding has been interpreted as evidence that only one of the two samples is remembered (i.e., food) and a response is made to the alternative comparison in the absence of memory for a food sample (i.e., by default; see Colwill, 1984; Sherburne \& Zentall, 1993a; Wilson \& Boakes, 1985). According to this hypothesis, the divergent functions occur because, on food sample trials, with an increasing retention interval and loss of memory for the food sample, accuracy would be expected to decline. On no-food sample trials, however, there should be no memory of a food sample, either initially or after an extended retention interval. Instead, a default response would be made in either case, and accuracy should remain high.

With regard to the present discussion, the fact that divergent retention functions are found following matching training with samples of food and no food has been taken as evidence that the pigeons are using retrospective rather than prospective codes (Grant, 1991). Presum- 
ably, prospective coding would generate a representation of one comparison or the other on all trials, and parallel retention functions would be found. However, unlike food and no-food sample conditional discriminations, when hue (e.g., red and green) samples are mapped, one to one, onto comparisons, the resulting retention functions are typically parallel. Grant (1991) reasoned that, if one pair of samples consisted of food and the absence of food, but many-to-one training encouraged prospective coding, pigeons should show parallel rather than divergent food/no-food retention functions when tested with delays.

Grant (1991) first trained pigeons on a hue sample conditional discrimination with one-to-one mapping of samples onto comparisons. For the many-to-one mapping group, he then added food and no-food sample trials to the task, so that there was now a many-to-one mapping of samples onto comparisons. For the one-to-one mapping group, the food and no-food sample trials were associated with new comparisons, so there was a one-toone mapping involving both sets of samples. When retention intervals were introduced on food and no-food sample trials for both groups, the one-to-one mapping group showed the typical divergent food/no-food retention functions. As predicted by the prospective coding account, however, retention functions on food and no-food sample trials for the many-to-one group were parallel.

Prospective coding processes can account for results of experiments in which transfer procedures have been used by invoking the notion of mediated generalization (Urcuioli, 1996). The mediated generalization hypothesis is based on Hull's (1939) notion of secondary generalization. According to this hypothesis, if two stimuli are associated with the same response (e.g., $S_{1}-R_{a}$ and $\mathrm{S}_{2}-\mathrm{R}_{\mathrm{a}}$ ), the stimuli also acquire the ability to produce implicit components of that response (e.g., $S_{1}-r_{a}$ and $\left.\mathrm{S}_{2}-\mathrm{r}_{\mathrm{a}}\right)$. Because the implicit responses also have stimulus properties (e.g., $S_{1}-r-S_{a}$ and $S_{2}-r_{a}-s_{a}$ ), those stimuli can then serve as added discriminative cues for other behavior (e.g., the implicit representations generated during $S_{1}-R_{a}$ and $S_{2}-R_{a}$ training can serve to mediate the new $S_{1}-R_{b}$ association established during interim training). Although Hull conceived of these mediators as overt fractional responses, whether one can actually observe the mediators is less important than the mediating relations that they engender (Urcuioli, 1996).

Thus, in the case of many-to-one conditional discrimination training, when two samples $\left(\mathrm{S}_{1}\right.$ and $\left.\mathrm{S}_{2}\right)$ are associated with a response to the same comparison $\left(C_{1}\right)$, each of those samples will come to elicit an anticipation or expectation of that comparison $c_{1}$. During interim training involving the association of $S_{1}$ with $C_{2}, S_{1}$ should continue to elicit $c_{1}$, and $c_{1}$ should become associated with $\mathrm{C}_{2}$. On test trials, $\mathrm{S}_{2}$ should elicit $\mathrm{c}_{1}$, and $\mathrm{c}_{1}$ should serve as a cue to select $\mathrm{C}_{2}$.

The mediated generalization hypothesis not only provides a mechanism to account for transfer effects fol- lowing many-to-one training (Urcuioli et al., 1995; Urcuioli et al., 1989; Wasserman et al., 1992) but also leads to the prediction that there should be little or no mediated generalization effect when original training involves a conditional discrimination with a one-to-many mapping of samples onto comparisons. Thus, if $S_{1}$ is associated with $C_{1}$ as well as $C_{2}$, an emergent relation would not be expected between the two comparisons, because the necessary mediators would not be in place. It may be that, after acquisition, both $\mathrm{C}_{1}$ and $\mathrm{C}_{2}$ anticipations are generated by $S_{1}$, but, at the start of interim training, presentation of a new sample $\left(S_{2}\right)$ would not be expected to elicit either $c_{1}$ or $c_{2}$. Although interim training should establish $c_{1}$ as a mediator for choice of $C_{1}$, that representation should not lead to choice of $\mathrm{C}_{2}$ when $\mathrm{S}_{1}$ is presented. Thus, mediated transfer would not be expected following one-to-many training.

As predicted by the mediated generalization hypothesis, the evidence for emergent relations between comparisons associated with the same sample following oneto-many matching training is rather weak. Zentall, Sherburne, and Steirn (1992) reported evidence for faster acquisition of a total reversal than of a partial reversal following one-to-many conditional discrimination training, but the effect was not very large in either of the two experiments reported. Furthermore, in experiments in which transfer designs have been used, the reported evidence for emergent relations has been either very weak (Urcuioli \& Zentall, 1993) or absent (Urcuioli et al., 1995).

\section{The Retrospective Coding Hypothesis}

Zentall et al. (1995) have proposed that retrospective sample representations (rather than prospective representations of the comparisons) may mediate emergent relations in many-to-one conditional discriminations. Although Urcuioli's (1996) model of mediated generalization is based on prospective representations, any mediator common to both samples would work equally well.

The first challenge is to show how a retrospective mediator that is common to samples associated with the same comparison might develop. Such a common mediator might take the following form: During many-to-one training, red and vertical samples, for example, could both be represented as red, and green and horizontal samples could both be represented as green. If this type of coding were to occur, then, during interim training, red samples, represented as red, would now be associated with a new comparison. Finally, because on test trials vertical samples should elicit a red representation (from original training), and red representations were associated with the new comparison during interim training, the transfer results found by Urcuioli et al. (1989) are readily predicted.

But what evidence is there for such common retrospective representations? Representations, by their nature, are difficult to specify. It has been proposed, how- 
ever, that one can distinguish between retrospective and prospective representations by systematically manipulating aspects of the samples or comparisons and assessing the effects of those manipulations on retention functions (Urcuioli \& Zentall, 1986). The argument is that similar representations should result in similarly sloping retention functions. Given that there is evidence that retention functions following hue matching (identity) are flatter than those following line orientation matching (see, e.g., Farthing et al., 1977), the nature of the representation can be inferred by manipulating either the sample dimension (hues vs. lines) or the comparison dimension (hues vs. lines) and determining which manipulation has an effect on the slope of the retention functions.

In the case of a simple one-to-one mapping design, results indicate that the sample dimension, rather than the comparison dimension, affects the slope of the retention functions (Urcuioli \& Zentall, 1986; Zentall, Jagielo, Jackson-Smith, \& Urcuioli, 1987; Zentall et al., 1989). Thus, it appears that retrospective representations of the samples are maintained in memory during acquisition of a conditional discrimination involving a one-to-one mapping of samples onto comparisons. But in the case of conditional discriminations involving many-to-one mappings, it is possible that, because there are at least four samples but only two comparisons, it may be more efficient to represent the comparisons prospectively.

Evidence for the retrospective representation of samples following many-to-one training comes from two sources. First, as mentioned earlier, evidence for the superiority of total versus partial reversals reported by Zentall et al. (1991) was found for the partial reversal group for which only the line orientation sample associations were reversed, but not for the second partial reversal group, for which only the hue sample associations were reversed. These data are consistent with the hypothesis that both hue and line orientation samples were commonly represented and that they were both represented as hues. According to this hypothesis, the partial reversal hues group and the total reversal group should have found the hue reversal to be of comparable difficulty. If line orientation samples were represented as hues, however, it should have been particularly difficult for the partial reversal lines group to have learned the reversal, because they would have had, first, to have learned to represent the line orientations as lines (rather than as hues) and, then, to have learned the new associations.

What determines which sample dimension will serve as the basis for the common representation following many-to-one training may depend on which of the sample-comparison associations are acquired first. In many cases, this would be the dimension involving the more salient, or more discriminable, stimuli. If, for example, the hue-sample/comparison associations are acquired first, association of the remaining samples (i.e., line orientations) with the same comparisons may be fa- cilitated if they, too, are represented as hues. In support of this hypothesis, as noted earlier, Zentall et al. (1993) found not only that fast learners showed emergent interference and facilitation effects and slow learners did not but also that fast learners acquired the hue sample associations at about the same rate as did slow learners, but they acquired the line orientation sample associations significantly faster than did the slow learners. If the fast learners represented the line orientations as hues, it would account for both the absence of faster acquisition of the hue sample associations and the faster acquisition of line orientation sample associations.

The second source of evidence for retrospective representations comes from research involving conditional discriminations with samples of food and no food. As noted earlier, when conditional discriminations involve food and no-food samples (or any sample dimension defined by the presence vs. the absence of an event; see Grant, 1991; Sherburne \& Zentall, 1993b), divergent retention functions are typically found on trials involving the two samples (Colwill, 1984; Grant, 1991; Sherburne \& Zentall, 1993a; Wilson \& Boakes, 1985). Furthermore, retention functions obtained following training with the typical hue or line orientation samples are generally parallel. Thus, if one trains pigeons with a manyto-one conditional discrimination involving food and nofood samples and red and green hue samples, the relative slopes of the resulting retention functions may suggest the nature of the underlying representations. For example, if following such many-to-one training the food/nofood sample retention functions are parallel, it might suggest that the hedonic samples were represented as hues. If, however, the hue sample retention functions diverge, it might suggest that the hues were represented as food and no food.

Zentall et al. (1995) found that, following training on a many-to-one conditional discrimination involving red and green hue and food/no-food samples, retention functions involving food/no-food sample trials were divergent (as would be expected following one-to-one training with those samples). However, retention functions involving hue sample trials were also divergent. Furthermore, the slopes of the functions on hue sample trials were similar to those of their corresponding food/nofood sample trials (see also Urcuioli, DeMarse, \& Zentall, 1994), an outcome consistent with the hypothesis that samples associated with the same comparison were commonly represented.

How can one reconcile these findings with those reported by Grant (1991)? Grant reported that, following many-to-one conditional discrimination training involving red and green hue and food/no-food samples, not only were the resulting hue sample trial retention functions parallel, but so, too, were the food/no-food sample trial retention functions. Grant (1991) interpreted his results as evidence for prospective coding (because divergent 
functions were not obtained). He concluded that the absence of divergent retention functions typically seen on food/no-food sample trials suggested that the food and no-food samples were not represented in the form of a retrospective single-code/default strategy but instead suggested evidence for a (perhaps more efficient) prospective comparison representation.

Reconciliation of Grant's (1991) data with results reported by Zentall et al. (1995) and Urcuioli et al. (1994) requires the careful comparison of differences in the training procedures used. Earlier, it was suggested that representations of the more discriminable sample pair might serve as the basis for representations of the less discriminable sample pair. Consistent with this hypothesis, when pigeons acquire many-to-one conditional discriminations involving hue samples and (biologically relevant) food/no-food samples, the food/no-food sample associations are acquired first. Thus, under these conditions, divergent hue sample and food/no-food sample retention functions would be expected.

Similar divergent functions were not found by Grant (1991), perhaps because, prior to many-to-one conditional discrimination training, Grant (1991) pretrained his pigeons with a one-to-one hue sample conditional discrimination. This pretraining may have ensured that the pigeons would represent the hue samples as hues. Then, when the food/no-food sample trials were introduced, the pigeons may also have represented the food and no-food samples as hues because associations between the hue representations and the comparisons had already been established during pretraining.

But why should a food sample elicit, for example, an appropriate red representation? One possibility is that, although food samples initially elicit food representations, prior to acquisition, those food representations are ineffective cues for comparison choice. Furthermore, occasionally, errors may be made in the nature of the sample representations or memory. If, in the case of a food sample, a red representation happened to be elicited, it would fortuitously serve as an effective cue for comparison choice (established during pretraining). Furthermore, it is likely that reinforcement of that choice would increase the tendency for later food samples to elicit red representations as well. On other trials during initial many-to-one training, food samples may erroneously elicit a green representation, but a green representation would provide a cue for an incorrect choice, and, thus, it is likely that the tendency for future food samples to elicit a green representation would decrease.

Taken as a whole, research with many-to-one matchingto-sample involving one pair of presence/absence samples suggests that Grant's (1991) interpretation may not be correct. When data from all of the experiments are considered, the retrospective coding of samples provides the most parsimonious account of the common representations established by many-to-one conditional discrimination training. Furthermore, there is also growing evidence that the common representations consist of (or are similar to) the earliest established representations that can serve as cues for comparison choice. Without pretraining, it is likely that this would be the more easily discriminated pair of samples or the samples that are most easily associated with their respective correct comparisons.

\section{THE RELATION BETWEEN COMMON REPRESENTATIONS AND TEMPORAL ENCODING}

Although the principle of contiguity has long been a cornerstone of learning theory, a number of well-established findings has required that it be qualified. For example, under many conditions, contiguity does not appear to be sufficient to establish a conditioned response. When a conditioned stimulus (CS) is presented simultaneously with an unconditioned stimulus (US), poor conditioning is typically found (see, e.g., Pavlov, 1927, p. 27). Furthermore, the well-established phenomena of higher order conditioning and sensory preconditioning suggest that contiguity is not necessary to establish conditioning (see, e.g., Egger \& Miller, 1962).

Temporal encoding theory, proposed by Matzel, Held, and Miller (1988), provides a representational mechanism to account for these apparent failures. According to this theory, the temporal relation between two stimuli is encoded along with the occurrence of the stimuli, and evidence for conditioning (in the form of a conditioned response, $\mathrm{CR}$ ) will be found only when the appropriate temporal relation is established between represented events. An important characteristic of the temporal encoding hypothesis is that associations are combined relationally to form a kind of temporal map in which common mediators can establish links between stimuli that have never been presented together. Thus, the temporal encoding hypothesis can account for the establishment of associations for which contiguity cannot play a direct role. In the case of simultaneous conditioning, although contiguity is sufficient to establish associations between the CS and the US, it may not be ideal for the occurrence of the CR.

The power of the temporal encoding hypothesis is in the rather interesting and, perhaps, counterintuitive predictions that one can derive from it. For example, if, following trace conditioning involving $\mathrm{CS}_{1} \rightarrow \mathrm{US}$, one presents $\mathrm{CS}_{1} \rightarrow \mathrm{CS}_{2}$, the temporal encoding hypothesis predicts that a $\mathrm{CS}_{1} \rightarrow \mathrm{CS}_{2} \rightarrow \mathrm{US}$ representation will be established, and good second-order conditioning should be found. However, if original training does not involve trace conditioning (i.e., the US follows the $\mathrm{CS}_{1}$ immediately), then, according to the temporal encoding hypothesis, the $\mathrm{CS}_{2}$ and US would occupy the same temporal representation, and evidence for second-order conditioning (in the form of a CR) should be poorer. These predictions have been confirmed by Cole, Barnet, and Miller (1995).

Although the Pavlovian procedures used to evaluate the temporal encoding hypothesis appear to be quite dif- 
ferent from those used in matching to sample, the temporal relations are not. In the matching procedure, when samples from different trials are associated with the same comparison, they may come to be represented on the same temporal map. And if they are, they could be represented contiguously, relative to their common comparison. If the temporal encoding hypothesis is applied to the many-to-one matching research described earlier, given the relationally simultaneous occurrence of the two samples associated with the same comparison, one might not expect to find a strong conditioned response as evidence of their association. However, when a new association is established between one of them and a novel comparison, one might expect to find evidence for the establishment of an association between the remaining sample and the novel comparison-and that is exactly what has been found.

\section{THE RELATION BETWEEN COMMON REPRESENTATIONS AND STIMULUS EQUIVALENCE}

The term stimulus equivalence has been used to describe formal relations among stimuli involving specific, untrained, emergent stimulus relations (Sidman, 1990). For a formal equivalence relation to exist among stimuli, three emergent properties must be demonstrated: reflexivity (identity or sameness; $A=A$ ), symmetry (bidirectionality or backward associativity; if $A=B$, then $B=A$ ), and transitivity (mediated associativity; if $\mathrm{A}=\mathrm{B}$ and $B=C$, then $A=C$ ). When applied to conditional discriminations, evidence for these emergent properties can be described more specifically.

\section{Reflexivity}

Reflexivity, or generalized identity, is demonstrated most directly when, following training with an identitymatching task, transfer is shown to new (unrelated) stimuli involving an identity relation. Although evidence for such transfer has sometimes been modest (Zentall \& Hogan, 1974, 1975, 1976, 1978), when training involves a large number of different stimuli (Wasserman, Hugart, \& Kirkpatrick-Steger, 1995; Young \& Wasserman, 1997) or when the novelty of the transfer stimuli can be reduced to avoid potential neophobia (Zentall, Edwards, Moore, \& Hogan, 1981), strong evidence for identity transfer has been reported.

\section{Symmetry}

Evidence for symmetry, or backward associations, using either Pavlovian conditioning procedures (Spetch, Wilkie, \& Pinel, 1981) or instrumental conditional discriminations, is quite limited (Gray, 1966; Hogan \& Zentall, 1977; Richards, 1988; Rodewald, 1974). In the instrumental procedure typically used, animals are trained on a conditional discrimination, and then the samples and comparisons are exchanged. Although the failure to find evidence for symmetry under these conditions could be attributed to an artifact (i.e., the novel locations of the stimuli on transfer trials), attempts to eliminate this problem (i.e., by giving the animals experience with the stimuli in the positions they will occupy in transfer) have not been particularly successful (Lipkens, Kop, \& Matthijs, 1986; Sidman et al., 1982).

When one of the events entering into the associative relation is biologically important (e.g., food), however, better evidence for symmetry has been found (Hearst, 1989; Sherburne \& Zentall, 1995; Zentall et al., 1992). Unfortunately, when biologically important events are predicted by neutral events, the behavior directed toward both may be similar (e.g., autoshaping), and the similarity in overt behavior directed to the two events may mediate the symmetry relation (K. J. Saunders, 1996; but see Hearst, 1989, and Zentall et al., 1992, Experiment 3, in which overt response mediation cannot account for the transfer effects found).

\section{Transitivity}

Most of the research on transitivity in animals has been done with Pavlovian conditioning procedures. Although these procedures have been referred to in other terms (i.e., sensory preconditioning and second-order conditioning), the procedures used in these experiments are logically the same as transitivity procedures. In the case of sensory preconditioning, for example, if $\mathrm{CS}_{1}(\mathrm{~A})$ is paired with $\mathrm{CS}_{2}(\mathrm{~B})$ and $\mathrm{CS}_{2}(\mathrm{~B})$ is paired with a $U S(C)$, an emergent relation may develop between $\mathrm{CS}_{1}(\mathrm{~A})$ and the US(C). Similarly, in the case of second-order conditioning, if $\mathrm{CS}_{1}(\mathrm{~B})$ is paired with a $\mathrm{US}(\mathrm{C})$ and $\mathrm{CS}_{2}(\mathrm{~A})$ is paired with $C S_{1}(B)$, an emergent relation may develop between $\mathrm{CS}_{2}(\mathrm{~A})$ and the US(C).

Although there is good evidence for such Pavlovian transitivity in both sensory preconditioning (Seidel, 1959) and second-order conditioning (Rescorla, 1980), evidence for transitivity has been more ephemeral in instrumental learning tasks. Steirn, Jackson-Smith, and Zentall (1991) found some evidence for transitivity when the mediated link, B, consisted of food, as opposed to its absence. In those experiments, pigeons were first trained on a simple successive discrimination (autoshaping) to associate a red stimulus $\left(A_{1}\right)$ with food $\left(B_{1}\right)$ and to associate a green stimulus $\left(A_{2}\right)$ with the absence of food $\left(B_{2}\right)$. The pigeons were then trained on a conditional discrimination in which samples of food $\left(B_{1}\right)$ indicated that a response to a vertical line $\left(C_{1}\right)$ would be reinforced and samples of no food $\left(B_{2}\right)$ indicated that a response to a horizontal line $\left(\mathrm{C}_{2}\right)$ would be reinforced. Finally, the pigeons were tested with red $\left(\mathrm{A}_{1}\right)$ and green $\left(\mathrm{A}_{2}\right)$ samples and a choice between vertical $\left(C_{1}\right)$ and horizontal $\left(C_{2}\right)$ comparisons. Food and no food were chosen as mediators, because it was felt that stimuli that differed in hedonic value would have relatively strong representations. Although significant transitivity effects were found in these experiments, the magnitude of the effects was small. 
More importantly, the choice of food and no food as mediators may have been ill advised, because, as was true of some of the research investigating emergent symmetry relations, similarity in behavior in the presence of the initial stimuli (the hues) and the presumed mediators (food and its absence) may have led to overt response mediation.

In contrast to Steirn et al.'s (1991) procedure, Kuno, Kitadate, and Iwamoto (1994) trained pigeons under conditions in which overt response mediation was unlikely because all of the stimulus events were arbitrary (nonhedonic). Although the evidence for emergent transitivity relations that they found was quite modest, it was presumably free from behavioral mediation effects.

Better evidence for emergent transitivity relations in animals was reported by Schusterman and Kastak (1993). What distinguished this study from other transitivity research with animals was the use of a sea lion as the subject and the large number (30) of potential transitive relations tested. Thus, although emergent transitive relations appear difficult to demonstrate in pigeons, they may occur more readily in "higher functioning" animals.

\section{Stimulus Equivalence}

Sidman (1990) proposed that a single test of stimulus equivalence could be conducted that incorporated all three presumed components of the formal definition. According to Sidman (1990), if one trained with the two associations needed to test for transitivity (i.e., $\mathrm{A}-\mathrm{B}$, and $B-C)$ and then found evidence for an emergent $\mathrm{C}-\mathrm{A}$ relation, it would demonstrate not only that an emergent transitive $\mathrm{A}-\mathrm{C}$ relation and its symmetry relation $\mathrm{C}-\mathrm{A}$ had developed but also that an emergent reflexive sampleA-comparison-A relation had developed. Reflexivity would be demonstrated because positive transfer implies that test comparison $\mathrm{A}$ is the same as training sample A.

Although Sidman (1990) may have been the first to describe the formal properties of this equivalence test, Kjeldergaard (1963; see also Jenkins, 1963) proposed a similar design to assess mediational learning in adult humans. Kjeldergaard also anticipated two other designs often used in the study of stimulus equivalence: the oneto-many design in which one sample is associated with more than one comparison (e.g., A-B, A-C) and then emergent relations between comparisons are tested (e.g., B-C; R. R. Saunders, Wachter, \& Spradlin, 1988) and the many-to-one design in which more than one sample is associated with a single comparison (e.g., A-B, C-B) and then emergent relations between samples are tested (e.g., A-C; Spradlin \& R. R. Saunders, 1986).

Some evidence for Sidman's (1990) version of stimulus equivalence has been found in animals. As an extension of the study already described, Schusterman and Kastak (1993) subjected a sea lion to Sidman's (1990) test for stimulus equivalence and found a high level of transfer on $\mathrm{C}-\mathrm{A}$ test trials following training with $\mathrm{A}-\mathrm{B}$ and $\mathrm{B}-\mathrm{C}$. It is difficult to estimate how many other attempts to demonstrate Sidman equivalence in animals have been made, but one notable failure with a chimpanzee was recently reported by Yamamoto and Asano (1995).

Research presented in the preceding sections suggests that there is some evidence that pigeons can show all three emergent relations defining stimulus equivalence: reflexivity, symmetry, and transitivity. On the other hand, although strong evidence for reflexivity has been found, the magnitude of symmetry and transitivity effects reported has been relatively small. Furthermore, when one excludes experiments in which overt response mediation may have played a role, the evidence is even weaker. Thus, overall, evidence for the emergence of the component relations presumed to underlie stimulus equivalence in animals has not been overwhelming. Nor has there been extensive evidence for equivalence (as defined by Sidman, 1990) in animals.

\section{Common Representations}

From the standpoint of stimulus equivalence theory (Sidman, 1990), the weak evidence for symmetry and transitivity relations in animals is somewhat surprising, because it has been argued that transfer effects found following many-to-one training provide evidence for both symmetry and transitivity (Spradlin, Cotter, \& Baxley, 1973; see Sidman \& Tailby, 1982, for a similar analysis of transfer effects following one-to-many conditional discrimination training). For example, if samples $\mathrm{A}$ and $\mathrm{B}$ are both associated with comparison $\mathrm{C}$, an emergent relation between $A$ and $B$ must be mediated by $C$ (transitivity), and, because the $\mathrm{C}-\mathrm{B}$ association was not trained, a backward association from $\mathrm{C}$ to $\mathrm{B}$ must also be present (symmetry). Clearly, strong emergent relations can be demonstrated in animals following many-to-one conditional discrimination training, as is shown by results of the experiments described in the section on common representation effects. Thus, it is unlikely that those relations are based on a combination of both symmetry and transitivity relations.

On the other hand, unlike the transfer design used in the pigeons research, in the procedure used by Spradlin and R. R. Saunders (1986), the critical test consisted of presentation of one of the presumed equivalent comparisons as a sample and of the other as one of the comparisons. This procedure is quite different from the transfer design used with animals. In pigeons, evidence for emergent relations following many-to-one training appears to depend on designs in which the samples and comparisons from training retain those functions during test.

K. J. Saunders (1996) has come to the same conclusion, although, according to her analysis, when emergent relations develop following training and test involving unidirectional procedures (i.e., procedures in which the samples and comparisons remain in their respective roles), the transfer effects found may be attributable to overt response mediation. As noted earlier, response mediation may, in fact, be present when differential behavior either is trained or occurs through pairing with different hedonic events (e.g., the presence vs. the absence of food). 
However, for cases in which all of the stimuli are nonhedonic (e.g., hues and shapes), this hypothesis is less supportable. Furthermore, as with early attempts to account for all learning in terms of overt behavior (Guthrie, 1935; Skinner, 1938), this hypothesis may not be falsifiable, because one can always posit the presence of residual differential behavior, even when no direct evidence for such overt mediators can be found. However, in the absence of overt response mediation, it would seem quite arbitrary to distinguish between mediators based on hypothetical differential responding and mediators based on hypothetical differential stimulus representations.

\section{Many-to-One Versus One-to-Many Training}

Sidman's (1990) analysis of stimulus equivalence is further challenged by differences in the results of experiments involving one-to-many training and those involving many-to-one training with animals. In principle, according to stimulus equivalence theory, the development of emergent stimulus relations following one-to-many training (Sidman \& Tailby, 1982) should be similar to that following many-to-one training (Spradlin et al., 1973). If sample $A$ is associated with comparisons $B$ and $C$, an emergent relation between $B$ and $C$ should develop, because $A$ can serve as a mediator (transitivity) and the association between $B$ and $A$ would be based on a backward association (symmetry). But as noted earlier, although strong evidence for emergent relations has been found following many-to-one training, the evidence for similar emergent relations following one-tomany training has been weak or absent. Apparently, many-to-one training establishes emergent relations that are different, certainly in magnitude but probably also in kind, from what develops during one-to-many training.

According to the present analysis, what distinguishes many-to-one from one-to-many training are the presumed common representations that can mediate the sample-comparison associations in the many-to-one design but not in the one-to-many design (see Urcuioli, 1996). If common representations can mediate transfer found following many-to-one training but not following one-to-many training, the difficulty in finding evidence for symmetry and transitivity should not be surprising.

In the case of tests for symmetry, whatever mediators are generated by presentation of a sample would be expected to be absent when samples and comparisons are interchanged. In the case of tests for transitivity, however, the possibility of a mediational account may be more promising. Using the Steirn et al. (1991) design described earlier, in Phase 1, red hue samples are followed by food. Thus, presentation of a red hue might result in the anticipation (or prospective representation) of food. In Phase 2, the actual presentation of food is associated with choice of a vertical line comparison. Finally, on test trials, presentation of a red hue stimulus is followed by a choice between vertical and horizontal lines. For such a mediational process to predict transfer effects would require not only prospective coding during original training but also the ability of a prospective representation of an event to substitute for the event itself.

Hall (1996) has recently suggested just such interchangeability between a representation (or image) of an event and the event itself. Hall (1996) proposed that, in the case of a one-to-many conditional discrimination, presentation of the sample should simultaneously activate representations of both potentially correct comparisons. Hall's (1996) prediction is that there should be evidence of such emergent relations between comparisons associated with the same sample, either following interim training with a new set of samples and one pair of comparisons from original training (see Urcuioli \& Zentall, 1993; Urcuioli et al., 1995) or when members of one pair of comparisons from original training are presented as samples (on successive trials) and the remaining comparisons are presented as comparisons (Sidman, 1971). Although evidence for such emergent relations following one-to-many conditional discrimination training is relatively weak in animals, Hall (1996) suggests that the three-phase interim-training design used in that research may have required a more complex chain of associations than the simple design used by Sidman with children (in which one of the original comparisons replaced the sample). When Hall, Ray, and Bonardi (1993) tested for the presence of emergent relations following training with a Pavlovian version of the one-to-many design, evidence comparable with that found with an analogue of the manyto-one procedure was found (see also Bonardi \& Hall, 1994; Bonardi, Rey, Richmond, \& Hall, 1993).

But if representations can substitute for the actual events, there should be stronger evidence for both transitivity and symmetry in animals. Hall (1996) suggests that the relatively poor evidence for transitivity in animals may be attributable to the fact that the samples are generally turned off before the comparisons are turned on. When the samples and comparisons remain presented together, Hall (1996) suggests that backward associations (between the initial link comparisons and samples) are permitted to form. If $\mathrm{A}-\mathrm{B}$ training results in the formation of B-A associations, then, together with later B-C training, the resulting design would be similar to one-tomany training. In the case of tests of symmetry, too, samples and comparisons have been interchanged following conditional discrimination training in which samples are turned off before comparisons are turned on.

But the associative processes involved when samples and comparisons are presented simultaneously may be quite different from those proposed here. Under conditions of simultaneous presentation, it is possible that the sample and correct comparison can become a compound stimulus, and associations between them (e.g., withinevent conditioning; Rescorla \& Durlach, 1981) would be expected. Such associations would be quite different 
from the emergent backward associations posited to develop when comparison presentation follows the offset of the sample.

At a more intuitive level, it seems to be unlikely that Hall's (1996) hypothesis that representations can substitute for the events themselves is correct. This deficiency can best be seen by considering the functional difference between food and its representation. For example, it would be surprising if the anticipation of eating would readily substitute for actually having eaten. If anticipations and the events themselves were interchangeable, one might expect those anticipations of food to interfere with further responses necessary to obtain food.

Notwithstanding Hall's ( 1996) attempts to account for the weak emergent relations typically found in animals on symmetry and transitivity tests and on tests following one-to-many conditional discrimination training, these results, together with the strong evidence of emergent relations typically found following many-to-one conditional discrimination training, suggest that representations do not readily substitute for the events themselves. Instead, a more parsimonious account of all of these data suggests that internal representations can enter into association with multiple stimuli and, thus, can function as a common node resulting in the development of untrained relations among those stimuli.

The superiority of emergent stimulus relations following many-to-one training, relative to tests of symmetry and transitivity, also has implications for the nature of the representation. For a transitive relation to be established, it must be the case that the initial link (A-B) in the relation involves a prospective representation of the middle term (B) that then substitutes for the actual initial event in the second link (B-C). Earlier, however, it was suggested that many-to-one matching established retrospective representations of one of the samples as a common mediator. Thus, the stronger evidence for transfer following many-to-one training than for that following transitivity training suggests that, in addition to the greater similarity between representations following many-to-one training, it may also be the case that those retrospective representations are stronger or more easily developed than are the prospective representations needed for transitive relations to be established.

It is now becoming clear that the way in which animals typically use common representations (e.g., following many-to-one matching-to-sample training) suggests that those relations are different from the relations that define stimulus equivalence. According to the theory of stimulus equivalence, stimuli that are members of an equivalence set should be interchangeable in other contexts. When stimuli are commonly represented, however, the conditions under which one stimulus can be substituted for another should be more limited. K. J. Saunders (1996) has suggested that most of the findings in which emergent stimulus relations have been found in animals have been limited to unidirectional procedures potentially involving response-mediated transfer. An im- portant exception is the many-to-one conditional discrimination transfer design in which it is not likely that response mediation plays an important role. However, two apparently critical aspects of that design are that the associations are unidirectional (symmetry relations or backward associations are not presumed to be involved) and that, unlike the transitivity design, the transfer design does not require that the animal substitute a representation of an event for the event itself.

Although the effects of mediation through common representation may not be the same as stimulus equivalence effects, one should not underestimate the implications of evidence of the generation of common representations for a general theory of learning. If animals can substitute the representation of a particular arbitrary stimulus for that of another, quite different arbitrary stimulus, it suggests that animals have a remarkably flexible capacity for representing or coding stimuli.

\section{CONCLUSIONS}

The law of effect does not address the relation of the nature of the outcome (reinforcer or punisher) to the nature of the association that it presumably strengthens or weakens (Thorndike, 1911). We now know that learning is not only affected by the valence of the reinforcer but both by its compatibility with the events that precede it (Garcia \& Koelling, 1966; Seligman \& Hager, 1972) and by the discriminative stimulus value of its anticipation (i.e., the differential outcomes effect; Trapold, 1970). When two stimuli are associated with the same outcome, they can often be substituted for one another in other contexts (Edwards, Jagielo, Zentall, \& Hogan, 1982; Peterson, 1984). This acquired equivalence effect, based on common outcomes, greatly expands the flexibility of organisms to categorize events according to their hedonic meaning and to use internally generated outcome representations as discriminative stimuli (Sherburne \& Zentall, 1998).

The kind of emergent relations demonstrated following many-to-one matching adds a level of abstraction to categorical flexibility. Not only do emergent relations develop between stimuli associated with the same outcome, but they can develop between stimuli associated with the same nonhedonic stimulus as well. Thus, stimulus representations in animals are not limited to biologically important events (e.g., food) but appear to include quite arbitrary events (e.g., hues and shapes). The fact that pigeons are capable of this level of flexible representation suggests that animals have considerably more cognitive (representational) capacity than has traditionally been assumed.

\section{REFERENCES}

BONARDI, C., \& HALL, G. (1994). Occasion setting renders stimuli more similar: Acquired equivalence between the targets of feature positive discriminations. Quarterly Journal of Experimental Psychology, 47B, 63-81. 
Bonardi, C., Rey, V., Richmond, M., \& Hall, G. (1993). Acquired equivalence of cues in pigeon autoshaping: Effects of training with common consequences and with common antecedents. Animal Learning \& Behavior, 21, 369-376.

Cole, R. P., Barnet, R. C., \& Miller, R. R. (1995). Temporal encoding in trace conditioning. Animal Learning \& Behavior, 23, 144-153.

ColwILL, R. M. (1984). Disruption of short-term memory for reinforcement by ambient illumination. Quarterly Journal of Experimental Psychology, 36B, 235-258

Edwards, C. A., Jagielo, J. A., Zentall, T. R., \& Hogan, D. E. (1982). Acquired equivalence and distinctiveness in matching-tosample by pigeons: Mediation by reinforcer-specific expectancies Journal of Experimental Psychology: Animal Behavior Processes, 8, 244-259.

EgGer, M. D., \& Miller, N. E. (1962). Secondary reinforcement in rats as a function of information value and reliability of the stimulus. Journal of Experimental Psychology, 64, 97-104.

Farthing, G. W., Wagner, J. W., Gilmour, S., \& Waxman, H. M. (1977). Short-term memory and information processing in pigeons Learning \& Motivation, 8, 520-532.

Garcia, J., \& Koelling, R. A. (1966). Relation of cue to consequence in avoidance learning. Psychonomic Science, 4, 123-124.

GRANT, D. S. (1982). Prospective versus retrospective coding of samples of stimuli, responses, and reinforcers in delayed matching-tosample by pigeons. Learning \& Motivation, 13, 265-280.

Grant, D. S. (1991). Symmetrical and asymmetrical coding of food and no-food samples in delayed matching in pigeons. Journal of Experimental Psychology: Animal Behavior Processes, 17, 186-193.

Gray, L. (1966). Backward association in pigeons. Psychonomic Science, 4, 333-334.

GuTHRIE, E. R. (1935). The psychology of learning. New York: Harper.

HALL, G. (1991). Perceptual and associative learning. Oxford: Oxford University Press.

HALL, G. (1996). Learning about associatively activated stimulus representations: Implications for acquired equivalence and perceptual learning. Animal Learning \& Behavior, 24, 233-255.

Hall, G., RaY, E., \& Bonardi, C. (1993). Acquired equivalence between cues trained with a common antecedent. Journal of Experimental Psychology: Animal Behavior Processes, 19, 391-399.

HEARST, E. (1989). Backward associations: Differential learning about stimuli that follow the presence versus the absence of food in pigeons. Animal Learning \& Behavior, 17, 280-290.

HOGAN, D. E., \& ZENTALL, T. R. (1977). Backward associative learning in the pigeon. American Journal of Psychology, 90, 3-15.

HONEY, R. C., \& HALL, G. (1989). The acquired equivalence and distinctiveness of cues. Journal of Experimental Psychology: Animal Behavior Processes, 15, 338-346.

HuLl, C. L. (1939). The problem of stimulus equivalence in behavior theory. Psychological Review, 46, 9-30.

Jenkins, J. J. (1963). Mediated associations: Paradigms and situations. In C. N. Cofer \& B. S. Musgrave (Eds.), Verbal behavior and learning: Problems and processes (pp. 210-245). New York: McGrawHill.

Kaiser, D. H., Sherburne, L. M., Steirn, J. N., \& Zentall, T. R. (1997). Perceptual learning in pigeons: Decreased ability to discriminate samples mapped onto the same comparison in many-toone matching. Psychonomic Bulletin \& Review, 4, 378-381.

KJeldergaARD, P. M. (1963). Transfer and mediation in verbal learning. In T. R. Dixon \& D. L. Horton (Eds.), Verbal behavior and general behavior theory (pp. 67-96). Englewood Cliffs, NJ: PrenticeHall.

Kuno, H., Kitadate, T., \& Iwamoto, T. (1994). Formation of transitivity in conditional matching to sample by pigeons. Journal of the Experimental Analysis of Behavior, 62, 399-408

LEA, S. E. G. (1984). In what sense do pigeons learn concepts? In H. L. Roitblat, T. G. Bever, \& H. S. Terrace (Eds.), Animal cognition (pp. 263-276). Hillsdale, NJ: Erlbaum.

LiPKENS, R, KoP, P. F., \& MatThiJs, W. (1986). A test of symmetry and transitivity in the conditional discrimination performance of pi- geons. Journal of the Experimental Analysis of Behavior, 49, 395 410 .

Matzel, L. D., Held, F. P., \& Miller, R. R. (1988). Information and the expression of simultaneous and backward associations: Implications for contiguity theory. Learning \& Motivation, 19, 317-344.

NAKAGAWA, E. (1986). Overtraining, extinction, and shift learning in a concurrent discrimination in rats. Quarterly Journal of Experimental Psychology, 38, 313-326.

Pavlov, I. P. (1927). Conditioned reflexes (G. V. Anrep, Trans.). London: Oxford University Press.

Peterson, G. B. (1984). How expectancies guide behavior. In H. L. Roitblat, T. G. Bever, \& H. S. Terrace (Eds.), Animal cognition (pp. 135-148). Hillsdale, NJ: Erlbaum.

ResCORLA, R. A. (1980). Pavlovian second-order conditioning. Hillsdale, NJ: Erlbaum.

Rescorla, R. A., \& Durlach, P. J. (1981). Within-event learning in Pavlovian conditioning. In N. E. Spear \& R. R. Miller (Eds.), Information processing in animals: Memory mechanisms (pp. 81-111). Hillsdale, NJ: Erlbaum.

RichaRds, R. W. (1988). The question of bidirectional associations in pigeons' learning of conditional discrimination tasks. Bulletin of the Psychonomic Society, 26, 577-579.

RODEWALD, H. K. (1974). Symbolic matching-to-sample by pigeons. Psychological Reports, 34, 987-990.

SAUNDERS, K. J. (1996). Derived stimulus control: Are there differences among procedures and processes? In T. R. Zentall \& P. M. Smeets (Eds.), Stimulus class formation in humans and animals (pp. 93-109). Amsterdam: North-Holland.

SAUNDERS, R. R., WACHTER, J., \& SPRADLIN, J. E. (1988). Establishing auditory stimulus control over an eight-member equivalence class via conditional discrimination procedures. Journal of the Experimental Analysis of Behavior, 49, 95-115.

Schusterman, R. J., \& KastaK, D. (1993). A California sea lion ( $\mathrm{Za}$ lophus Californianus) is capable of forming equivalence relations. Psychological Record, 43, 823-839.

SEIDEL, R. J. (1959). A review of sensory preconditioning. Psychological Bulletin, 56, 58-73.

Seligman, M. E. P., \& Hager, J. L. (Eds.) (1972). Biological boundaries of learning. New York: Appleton-Century-Crofts.

Sherburne, L. M., \& Zentall, T. R. (1993a). Asymmetrical coding of food and no-food events by pigeons: Sample pecking versus food as the basis of the sample code. Learning \& Motivation, 24, 141155 .

Sherburne, L. M., \& Zentall, T. R. (1993b). Coding of feature and no-feature events by pigeons performing a delayed conditional discrimination. Animal Learning \& Behavior, 21, 92-100.

Sherburne, L. M., \& Zentall, T. R. (1995). Delayed matching in pigeons with food and no-food samples: Further examination of backward associations. Animal Learning \& Behavior, 23, 177-181.

Sherburne, L. M., \& Zentall, T. R. (1998). The differential outcomes effect in pigeons is not reduced by eliminating responseoutcome associations: Support for a two-process account. Animal Learning \& Behavior, 26, 378-387.

Sidman, M. (1971). Reading and auditory-visual equivalences. Journal of Hearing \& Speech Research, 14, 5-13.

Sidman, M. (1990). Equivalence relations: Where do they come from? In H. Lejeune \& D. Blackman (Eds.), Behavior analysis in theory and practice: Contributions and controversies (pp. 93-114). Hillsdale, $\mathrm{NJ}$ : Erlbaum.

Sidman, M., Rauzin, R., Lazar, R., Cunningham, S., Tailby, W., \& CARRIGAN, P. (1982). A search for symmetry in the conditional discrimination of rhesus monkeys, baboons, and children. Journal of the Experimental Analysis of Behavior, 37, 23-44.

Sidman, M., \& TaIlby, W. (1982). Conditional discrimination vs. matching-to-sample: An expansion of the testing program. Journal of the Experimental Analysis of Behavior, 37, 5-22.

SKINNER, B. F. (1938). The behavior of organisms. New York: AppletonCentury.

Spear, N. E., Kraemer, P. J., Molina, J. C., \& Smoller, D. E. (1988). 
Developmental change in learning and memory: Infantile disposition for unitization. In J. Delacour \& J. C. S. Levy (Eds.), Systems with learning and memory abilities (pp. 27-52). Amsterdam: Elsevier.

SPEAR, N. E., \& MOLINA, J. C. (1987). The role of sensory modality in the ontogeny of stimulus selection. In N. Krasnegor, E. M. Blass, M. A. Hofer, \& W. P. Smotherman (Eds.), Perinatal development: $A$ psychobiological perspective (pp. 83-110). Orlando, FL: Academic Press.

SpetCh, M. L., Wilkie, D. M., \& Pinel, J. P. J. (1981). Backward conditioning: A reevaluation of the empirical evidence. Psychological Bulletin, 89, 163-175.

Spradlin, J. E., CotTer, V. W., \& BaXley, N. (1973). Establishing a conditional discrimination without direct training: A study of transfer with retarded adolescents. American Journal of Mental Deficiency, 77, 556-566.

Spradlin, J. E., \& SaUnders, R. R. (1986). The development of stimulus classes using matching-to-sample procedures: Sample classification versus comparison classification. Analysis \& Intervention in Developmental Disabilities, 6, 41-58.

Steirn, J. N., Jackson-Smith, P., \& Zentall, T. R. (1991). Mediational use of internal representations of food and no-food events by pigeons. Learning \& Motivation, 22, 353-365.

THORNDIKE, E. L. (1911). Animal intelligence. New York: Macmillan.

TRAPOLD, M. A. (1970). Are expectancies based on different positive reinforcing events discriminably different? Learning \& Motivation, $1,129-140$.

URCUIOLI, P. J. (1996). Acquired equivalences and mediated generalization in pigeon's matching-to-sample. In T. R. Zentall \& P. M Smeets (Eds.), Stimulus class formation in humans and animals (pp. 55-70). Amsterdam: North-Holland.

Urcuioli, P. J., DeMarse, T., \& Zentall, T. R. (1994). Some properties of many-to-one matching with hue, response, and food samples Retention and mediated transfer. Learning \& Motivation, 25, 175 . 200 .

UrCuioli, P. J., \& Zentall, T. R. (1986). Retrospective memory in pigeons' delayed matching-to-sample. Journal of Experimental Psychology: Animal Behavior Processes, 12, 69-77.

Urcuioli, P. J., \& ZenTall, T. R. (1993). A test of comparisonstimulus substitutability following one-to-many matching by pigeons. Psychological Record, 43, 725-744.

Urculoli, P. J., Zentall, T. R., \& DeMarse, T. (1995). Transfer to derived sample-comparison relations by pigeons following many-toone versus one-to-many matching with identical training relations. Quarterly Journal of Experimental Psychology, 48B, 158-178

Urcuioli, P. J., Zentall, T. R., Jackson-Smith, P., \& Steirn, J. N. (1989). Evidence for common coding in many-to-one matching: Retention, intertrial interference, and transfer. Journal of Experimental Psychology: Animal Behavior Processes, 15, 264-273.

Wasserman, E. A., DeVolder, C. L., \& Coppage, D. J. (1992). Nonsimilarity based conceptualization in pigeons via secondary or mediated generalization. Psychological Science, 3, 374-379.

Wasserman, E. A., Hugart, J. A., \& KirkPatrick-Steger, K. (1995). Pigeons show same-different conceptualization after training with complex visual stimuli. Journal of Experimental Psychology: Animal Behavior Processes, 21, 248-252.

WILSON, B., \& BOAKES, R. A. (1985). A comparison of the short-term memory performance of pigeons and jackdaws. Animal Learning \& Behavior, 13, 285-290.

Yamamoto, J., \& Asano, T. (1995). Stimulus equivalence in a chimpanzee (Pan troglodytes). Psychological Record, 45, 3-21.

YounG, M. E., \& Wasserman, E. A. (1997). Entropy detection by pigeons: Response to mixed visual displays after same-different discrimination training. Journal of Experimental Psychology: Animal Behavior Processes, 23, 157-170.

Zentall, T. R., Edwards, C. A., Moore, B. S., \& Hogan, D. E. (1981). Identity: The basis for both matching and oddity learning in pigeons. Journal of Experimental Psychology: Animal Behavior Processes, 7, 70-86.

Zentall, T. R., \& Hogan, D. E. (1974). Abstract concept learning in the pigeon. Journal of Experimental Psychology, 102, 393-398.

Zentall, T. R., \& Hogan, D. E. (1975). Concept learning in the pigeon: Transfer of matching and nonmatching to new stimuli. American Journal of Psychology, 88, 233-244.

Zentall, T. R., \& Hogan, D. E. (1976). Pigeons can learn identity, difference, or both. Science, 191, 408-409.

Zentall, T. R., \& Hogan, D. E. (1978). Same/different concept learn. ing in the pigeon: The effect of negative instances and prior adaptation to the transfer stimuli. Journal of the Experimental Analysis of Behavior, 30, 177-186.

Zentall, T. R., Jagielo, J. A., Jackson-Smith, P., \& Urcuioli, P. J. (1987). Memory codes in pigeon short-term memory: Effect of varying number of sample and comparison stimuli. Learning \& Motivation, 18, 21-33.

Zentall, T. R., Sherburne, L. M., \& Steirn, J. N. (1992). Development of excitatory backward associations during the establishment of forward associations in a delayed conditional discrimination by pigeons. Animal Learning \& Behavior, 20, 199-206.

Zentall, T. R., Sherburne, L. M., \& UrCuioli, P. J. (1993). Common coding by pigeons in a many-to-one delayed matching task as evidenced by facilitation and interference effects. Animal Learning \& Behavior, 21, 233-237.

Zentall, T. R., Sherburne, L. M., \& Urculoli, P. J. (1995). Coding of hedonic and nonhedonic samples by pigeons in many-to-one delayed matching. Animal Learning \& Behavior, 23, 189-196.

Zentall, T. R., Steirn, J. N., Sherburne, L. M., \& Urculoli, P. J. (1991). Common coding in pigeons assessed through partial versus total reversals of many-to-one conditional and simple discriminations. Journal of Experimental Psychology: Animal Behavior Processes, 17, 194-201.

Zentall, T. R., Urcuioli, P. J., Jagielo, J. A., \& Jackson-Smith, P. (1989). Interaction of sample dimension and sample-comparison mapping on pigeons' performance of delayed conditional discriminations. Animal Learning \& Behavior, 17, 172-178.

(Manuscript received December 17, 1997; revision accepted for publication May 12, 1998.) 